\title{
Large-scale facilitation of a sessile community by an invasive habitat-forming snail
}

\author{
Jakob Thyrring • Mads Solgaard Thomsen • \\ Thomas Wernberg
}

Received: 26 February 2013/Revised: 7 June 2013/Accepted: 19 June 2013/Published online: 2 July 2013

(C) Springer-Verlag Berlin Heidelberg and AWI 2013

\begin{abstract}
We provide an example of extensive facilitation of a sessile community throughout an invaded estuary by the invasive snail Batillaria australis. We show that $B$. australis greatly increases a limiting resource (attachment space) to a community of sessile organisms and estimate that a large part of the invaded estuary now contain ca. 50 times more sessile individuals associated with the invader than all native snails combined. We argue that native snails are unlikely to have been dramatically reduced by the invader, and we therefore suggest that the shell-attached sessile community, as a functional group, has benefitted significantly from this invasion. These results expand the
\end{abstract}

Communicated by H.-D. Franke.

Electronic supplementary material The online version of this article (doi:10.1007/s10152-013-0363-2) contains supplementary material, which is available to authorized users.

J. Thyrring $(\bowtie)$

Department of Bioscience, Arctic Research Centre,

Aarhus University, C. F. Møllers Allé 8, Building 1110,

8000 Aarhus C, Denmark

e-mail: thyrring@biology.au.dk

M. S. Thomsen

Marine Ecology Research Group, School of Biological

Sciences, University of Canterbury, Private Bag 4800,

Christchurch, New Zealand

M. S. Thomsen · T. Wernberg

UWA Oceans Institute and School of Plant Biology,

University of Western Australia, Hackett Drive,

Crawley, WA 6009, Australia

T. Wernberg

Australian Institute of Marine Science, 39 Fairway,

Crawley, WA 6009, Australia current understanding of how invaded marine systems respond to habitat-forming invaders.

Keywords Biodiversity - Positive effects . Hard substratum · Epibiota - Habitat cascade . Facilitation cascade

\section{Introduction}

When non-indigenous species invade new communities, they interact with and have effects on many resident species (Staehr et al. 2000; Crooks 2009; Altieri et al. 2010). Similar to any other ecological network of interactions, this leads to some residents being adversely affected while others benefit. Ecologists have traditionally focused on how negative species interactions structure natural communities, but intensive research on positive effects is rectifying this imbalance, resulting in a more nuanced 'modern ecology' (Stachowicz 2001). However, the traditional perception of nature, where negative interactions are most important, still dominates invasion ecology (Rodriguez 2006; Bulleri 2009). A key mechanism whereby marine invaders can have positive impacts on local species is via habitat formation (Crooks 2002; Bulleri 2009; Thomsen et al. 2010a), a process that is particularly important for shell-forming species (epibiosis, reviewed in Gutierrez et al. 2003; Wahl 2009). Many studies have documented facilitation from invasive marine shell-formers, typically focusing on specific positively affected species (e.g. Wonham et al. 2005) or on community facilitation in a specific habitat or from a few study sites (e.g. Gribben et al. 2009). However, we are not aware of studies that have quantified community facilitation across multiple habitats and throughout an invaded system. Such 
large-scale community facilitation is most likely to occur when an invader provides a novel function or greatly increases the availability of a limiting resource and is abundant in the major habitats within the invaded system (Crooks 2002; Thomsen et al. 2010a).

Sessile species typically live attached to hard substratum, a strongly limited resource in most estuaries where sedimentary soft bottom prevails. Abiotic hard substratum (e.g. rocks, boulders) is at high risk of burial by sediments over time, but biotic shell-formers can remain on the sediment surface and thereby provide attachment space for sessile organisms (this resource provision also depend on the species abundance, size, longevity, shell properties, behaviour, and local abiotic conditions) (Gutierrez et al. 2003; Gribben et al. 2009; Wahl 2009). We recently documented that Batillaria australis has invaded the Swan River Estuary (the only invaded estuary in Western Australia) and that $B$. australis today is by far the most abundant snail in this estuary (Thomsen et al. 2010b). We also made the qualitative observations that sessile organisms are common on the shell of this invader.

The aims of our study were here to (a) quantify the sessile communities found on dominant shell types in key habitats in the Swan River Estuary and (b) combine these data with known shell densities to quantify and compare sessile communities associated with the invader versus native shell-formers throughout key habitats in the estuary.

\section{Materials and methods}

From October to December 2011 (austral spring and early summer), we collected 3,226 shells randomly by snorkelling, covering paired seagrass beds and interspersed sandflats shallower than $3 \mathrm{~m}$ depth at 13 random sites (Fig. 1) distributed throughout the Swan River Estuary. At each site, visual searches covering $150 \mathrm{~m} \times 150 \mathrm{~m}$ were made for 60-90 min. The 3,226 shells represented 7 types of shells, including 5 forms of $B$. australis (Bat) and two native species: 'Bat Gra+' = live adult B. australis with attached dense fronds of the coarsely branched red alga Gracilaria Comosa $(n=233$ from seagrass beds vs. 243 from interspersed sand-flats), 'Bat Gra-' = live adult $B$. australis without $G$. $\operatorname{comos} a(n=410$ vs. 250$)$, 'Bat Small' $=B$. australis recruits with shell length less than $1.3 \mathrm{~cm}(n=81$ vs. 65), 'Bat Empty' = empty shells of adult B. australis $(n=241$ vs. 250$)$, 'Bat Hermit' $=$ shells of adult B. australis occupied by hermit crabs ( $n=240$ vs. 250 ), 'Bedeva' = Bedeva paiva $\quad(n=204 \quad$ vs. 194$), \quad$ and 'Nassarius' = Nassarius pauperatus ( $n=287$ vs. 278$)$. Most shell types were found in both habitats at most sites, except that we found few $B$. australis recruits and there were no seagrass beds at site 2 (see Fig. 1) (see online S1 for replication level for each shell type). These shell types comprise $>99 \%$ of all snail shells found in this system (Thomsen et al. 2010b). Shells were brought to the laboratory, and sessile epibionts directly attached to the shells were identified and quantified under a dissection microscope. We estimated percentage cover of modular organisms (e.g. encrusting seaweeds and bryozoa) and counted solitary organisms (e.g. Chaetomorpha linum, Gracilaria comosa) on each shell. Subsequently, epibiont data (see Fig. 2b, c) were combined with shell abundance data (from Thomsen et al. 2010b), and the spatial extent of the sampled region [Fig. 1; the area that is shallower than $3 \mathrm{~m}$ in the middle and lower Swan River Estuary is ca. $10 \mathrm{~km}^{2}$ (pers. com. B. Marillier) of which ca. $5.5 \mathrm{~km}^{2}$ are seagrass beds (Hillman et al. 1995)], to calculate region-wide abundances of solitary and modular sessile organisms associated with invasive versus native shells, for example, sessile organisms per region $=$ sessile organisms per shell $\times$ shells per habitat $\times$ habitat per region. We also scaled up percentage

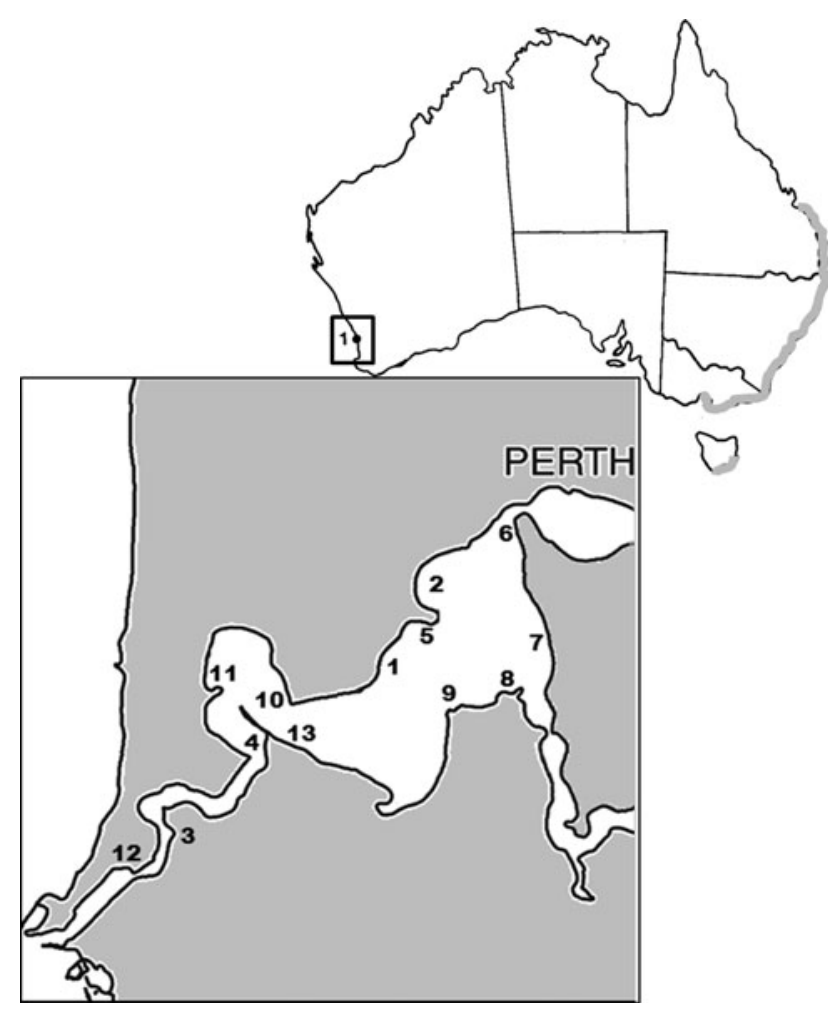

Fig. 1 Map of global distribution of Batillaria australis. Grey line native region. Black circle (Swan River Estuary, Perth) invaded region. Insert map of 13 study sites in the Swan River Estuary. 1 Charles Court, 2 Matilda Bay*, 3 Leeuwin, 4 Chidley Point, 5 J.H. Abrahams, 6 Mills Point, 7 Como, 8 Heathcote, 9 Jeff Joseph Reserve, 10 Point Resolution, 11 Freshwater Bay, 12 Gilbert Fraser, 13 Point Walter. *No seagrass beds at this location. The middle and lower Swan River Estuary is ca. $26 \mathrm{~km}^{2}$ (compared to $7.8 \mathrm{~km}^{2}$ for the two upstream river regions), where ca. $10 \mathrm{~km}^{2}$ is shallower than $3 \mathrm{~m}$ (pers. com. B. Marillier) of which ca. $5.5 \mathrm{~km}^{2}$ are covered by seagrass (Hillman et al. 1995) 
cover of solitary organisms to $\mathrm{m}^{2}$ per sampled region using the following shell sizes: large $B$. australis $=4.7 \mathrm{~cm}^{2}$, small B. australis $=1.5 \mathrm{~cm}^{2}, B$. paiva $=3.5 \mathrm{~cm}^{2}, N$. pauperatus $=1.5 \mathrm{~cm}^{2}$ (Thomsen et al. unpublished data).

We used two-way PERMANOVA based on Euclidian distances to test for the effect of habitat (fixed factors) and shell type (fixed factors) on taxonomic richness and density of solitary and modular epibionts (999 permutations) (Andersen et al. 2008). Data were $\log x+1$ transformed to sile organisms per shell with $95 \%$ confidence limits for each habitat (using sites as replicates), and differences between mean values were quantified using PERMANOensure variance homogeneity. We report densities of sesVA pairwise comparison with paired $t$ tests. Mean values

were considered significantly different when $p<0.05$. The region-wide calculations of sessile communities on different shell types were shown without errors because error estimates do not exist for sand and seagrass areas from the Swan River Estuary.

\section{Results}

We found no significant 'habitat $\mathrm{x}$ shell type' interaction effects and no single factor effects of 'habitat' on differences in sessile organisms attached to shells from seagrass beds versus sand-flats ( $p>0.05$ for all three tests) (Fig. 2a-c, online S2-3). However, we found strong

Fig. 2 Sessile community attached to invasive and native snail shells in the Swan River Estuary. a-c Taxonomic richness and density of solitary and modular sessile organisms found on shells in the Swan River Estuary in seagrass beds (black circles) versus sand-flats (grey circles). d Shell densities. e-f Total abundances of solitary and
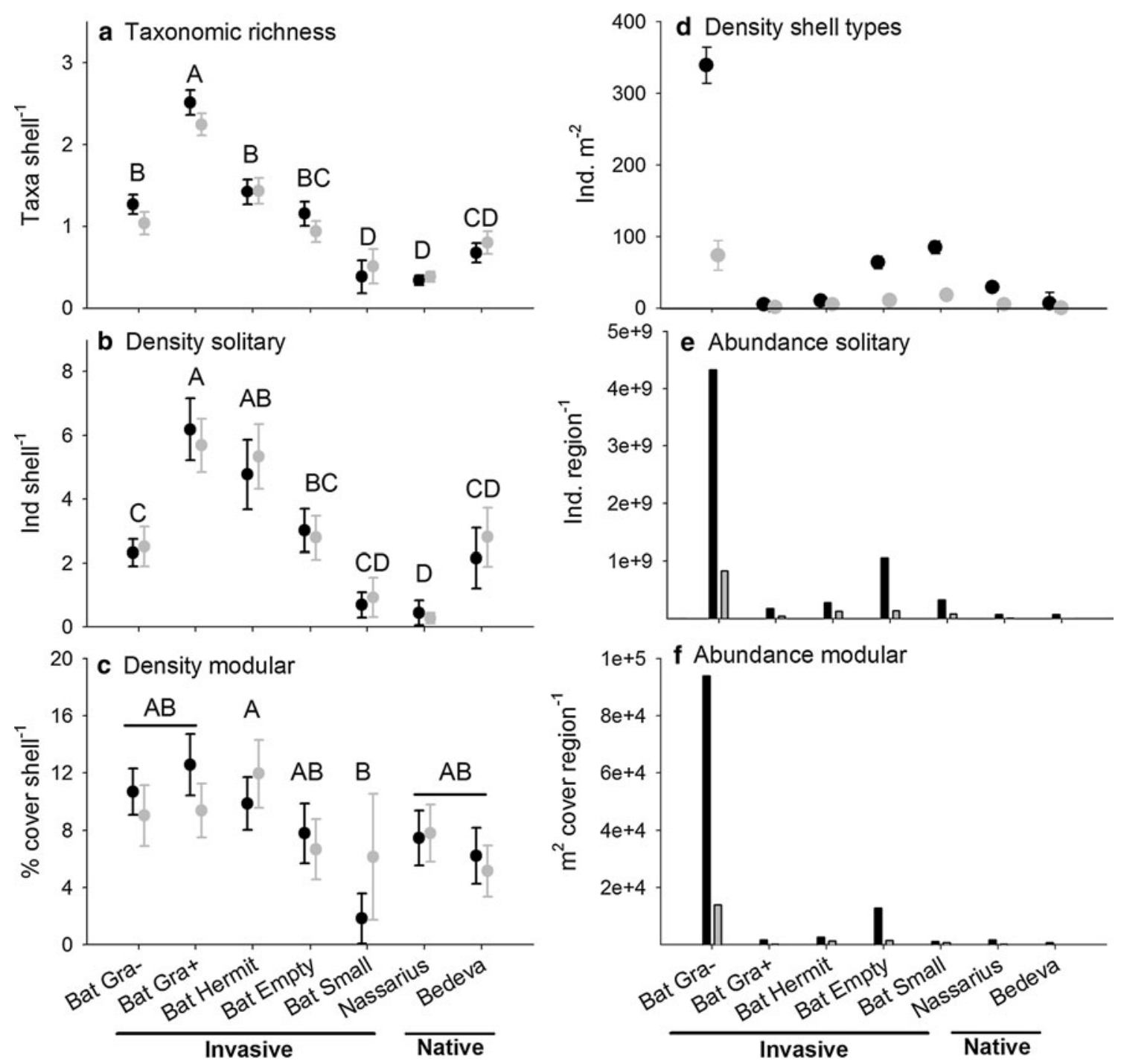

modular sessile organisms associated with dominant shell types in the middle and lower Swan River Estuary, shallower than $3 \mathrm{~m}$. Different letters indicate a significant difference $(p<0.05)$ with error bars $95 \%$ confidence limits (see online S2-3 for statistical results) 
patterns among shell types ( $p<0.001$ for all three tests). For taxonomic richness (Fig. 2a), we found most taxa associated with live adult B. australis with $G$. comosa attached, and least on B. australis recruits and Nassarius pauperatus (the remaining three shell types were in between). This pattern was almost identical for counts of solitary sessile organisms (Fig. 2b), but less clear for cover values of modular organisms, where taxonomic richness typically overlapped between species (but with almost the same pattern, Fig. 2c). Sessile species were, across the sampled region, overwhelmingly associated with live adult $B$. australis without $G$. comosa from seagrass beds and sand-flats, as well as empty $B$. australis shells from seagrass beds (Fig. 2e-f).

\section{Discussion}

The lowest taxonomic richness and density of solitary and modular sessile organisms was found on $B$. australis recruits and $N$. pauperatus. A simple explanation is that $N$. pauperatus often bury themselves when not feeding, leaving little time for epibiont settlement. Furthermore, $B$. australis recruits and $N$. pauperatus have the smallest shells and, in the case of $N$. pauperatus, are short-lived (Brearley 2005), i.e. sessile organisms have little space or time to settle and grow (Wernberg et al. 2010). The high richness and densities of sessile organisms found on live adult B. australis with $G$. comosa attached is partly explained by sampling methodology; by default, this shell type always has a minimum of 'one species and several individuals' (=dense G. comosa). Nevertheless, this still represents a true epibiota response and not a sampling artefact.

Our data suggest that $98 \%$ of all sessile organisms attached to snail shells in the most common habitats of the Swan River Estuary are associated with the invader. Importantly, the large differences in shell densities (Fig. 2d) were more important in determining region-wide community abundances, than how much epibiota was attached to individual shell types (Fig. 2b-c). We therefore conclude that these sessile communities, which inhabit snail shells, are likely to have benefitted significantly from the invasion of $B$. australis. We envision a few objections to this conclusion. First, we did not sample deep or lowsalinity regions within the Swan River Estuary. However, these regions contain relatively few sessile organisms attached to hard substratum (pers. obs.), probably because few habitat-formers and sessile organisms tolerate these habitats that are characterized by high sedimentation and sediment organic matters, low oxygen, light, and/or low salinity (Brearley 2005). Our data are therefore applicable in most areas of the Swan River Estuary where sessile communities are abundant. Second, our analysis assumes that native sessile species have not been dramatically reduced by $B$. australis. There are currently no data to suggest detrimental invasion effects on other shell-formers, like N. pauperatus or Bedeva paiva, that also can be hosts to sessile epibionts (Brearley 2005). For example, analysis of $100 \mathrm{~s}$ of sediment cores do not suggest any large pool of empty native shells (unpublished data and Thomsen et al. $2010 \mathrm{~b}$ ), in contrast to empty shells of the invader that can be found in the tens of 1,000 s in 'graveyards' (Fig. 3). We have also shown that even at extremely high $B$. australis densities, all three snail species co-occur (Thomsen et al. 2012). Furthermore, given that only few organisms are found attached to $N$. pauperatus (Fig. 2), even unrealistically high pre-invasion densities would not affect our conclusion. Third, B. paiva predates on mollusks and is therefore likely to have benefitted from the invasion because B. australis could be a new food resource. The final objection would be that alternative hard substrates exist in the Swan River Estuary, e.g. rocks, boulders and pilings, and non-snail habitat-formers such as bivalves and seagrasses (Halophila ovalis). However, this does not change our conclusion with respect to region-wide facilitation of sessile communities per se, but downgrades the importance of invader facilitation if these alternative substrates are ubiquitous and heavily fouled by similar species. A future study should therefore quantify the abundance of these types of substrates and their sessile communities, although our preliminary observations suggest that live buried bivalves contain virtually no sessile organisms, that abiotic substrates are scattered mainly 'surviving' sedimentation at shallow wave-exposed sites, and that both abiotic substrates and seagrasses support somewhat different sessile communities compared to B. australis (e.g. we have not found $G$. comosa or $C$. linum attached to seagrasses). We emphasize that our data address potential impact on sessile organisms; supplementary studies are needed to document impacts on other biotic communities in the Swan River Estuary, including infaunal invertebrates, mobile invertebrates, meiofauna, microbes, drifting seaweeds, and fish and birds. Nevertheless, our data provide a rare example of region-wide facilitation of a sessile community by an invasive snail, through increased provision of a limited resource (attachment space). We also suggest that this process extends beyond the facilitated sessile organisms, as these sessile organisms themselves are 'secondary habitat-formers/modifiers' that, like the 'primary habitat-formers/modifiers' (the shell-forming invader), provide living space, predation refugium, and food resources to mobile invertebrate 'end-users', including polychaetes, crustaceans, and small gastropods (Thomsen et al. 2010a). This 'habitat cascades' process (Thomsen et al. 2010a) is particularly important for 


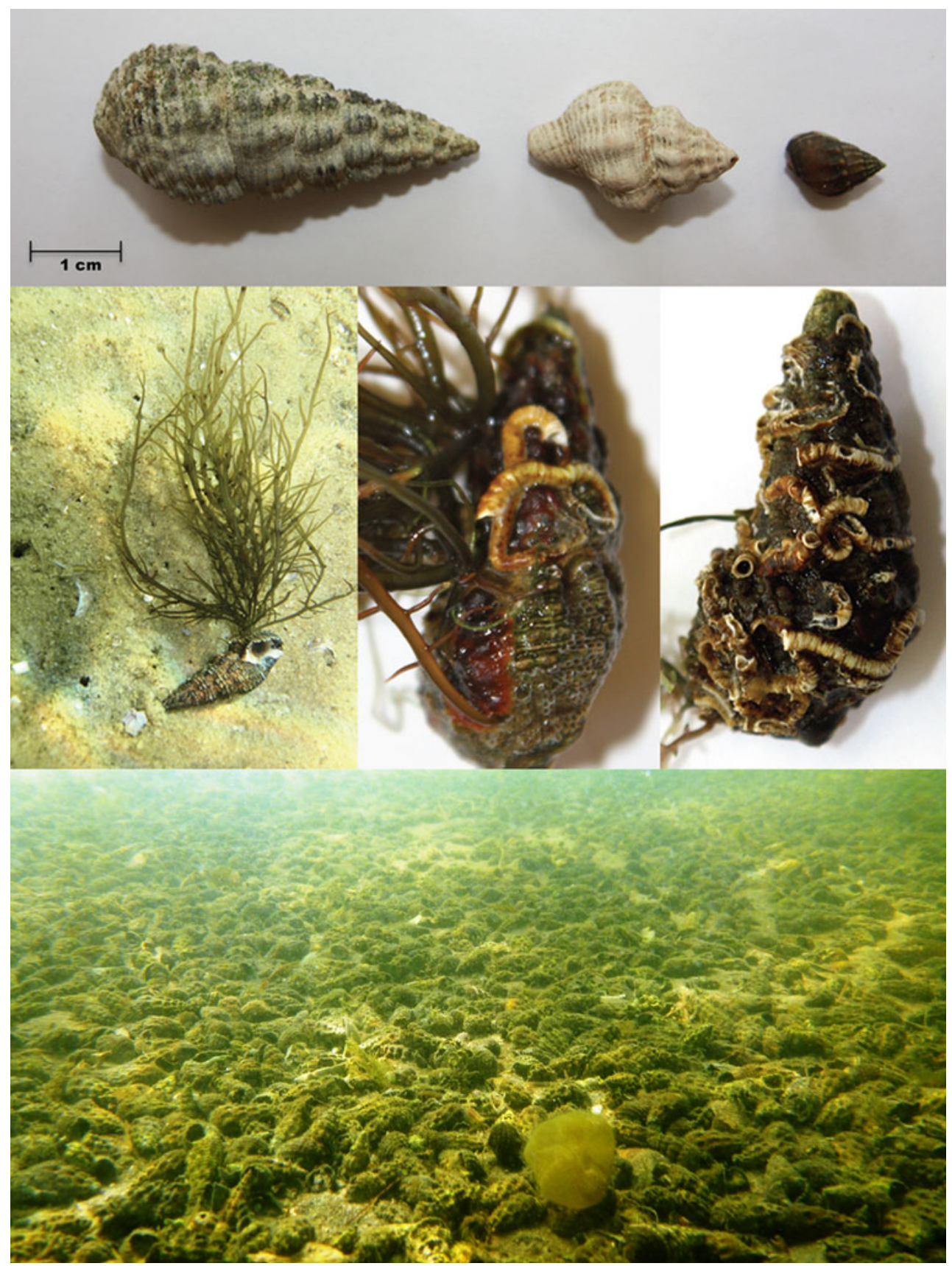

Fig. 3 Photographs of major shell types: top from left: large and live B. australis, B. paiva, and N. pauperatus; Middle from left: buried large live B. australis with dense G. comosa, close-up of attachments

B. australis with attached G. comosa, because this seaweed can grow into large fronds that dominate the habitat structures on unvegetated sand-flats and thereby facilitate communities of mobile invertebrates (Thomsen et al. 2010a; Thomsen et al. 2012). Finally, we suggest that invasion ecologists should investigate the prevalence and context whereby large-scale community-wide facilitation occurs (is this process rare in nature or has research been of holdfasts, and B. australis shell occupied by hermit crab covered in Pomatoceras polychaetes; Bottom: example of 'graveyard' consisting entirely of B. australis shells

biased?) and what, if any, functional groups and alternative communities are negatively affected when community facilitation is reported.

Acknowledgments J.T. was supported by a travel grant from Oticon Fonden, M.S.T. was supported by a Rising Star travel grant from the Australian National Network in Marine Science, and T.W. was supported by the Australian Research Council. We thank B. Marillier and K. Kilminster for information about Swan River Estuary. 


\section{References}

Altieri AH, van Wesenbeeck BK, Bertness MD, Silliman BR (2010) Facilitation cascade drives positive relationship between native biodiversity and invasion success. Ecology 91:1269-1275

Andersen MJ, Gorley RN, Clarke KR (2008) PERMANOVA for PRIMER: guide to software and statistical methods. PRIMER-E Ltd, Plymouth

Brearley A (2005) Ernest Hodgkin's Swanland. Estuaries and coastal lagoons in South Western Australia. University of Western Australia Press, Perth

Bulleri F (2009) Facilitation research in marine systems: state of the art, emerging patterns and insights for future developments. J Ecol 97:1121-1130

Crooks JA (2002) Characterizing ecosystem-level consequences of biological invasions: the role of ecosystem engineers. Oikos 97:153-166

Crooks JA (2009) The role of exotic marine ecosystem engineers. In: Rilov G, Crooks J (eds) Biological invasions in marine ecosystems. Springer, Berlin, pp 287-304

Gribben PE, Byers J, Clements M, McKenzie LA, Steinberg PD, Wright JT (2009) Behavioural interactions between ecosystem engineers control community species richness. Ecol Lett 12:1127-1136

Gutierrez JL, Jones CG, Strayer DL, Iribarne OO (2003) Mollusks as ecosystem engineers: the role of shell production in aquatic habitats. Oikos 101:79-90

Hillman K, McComb AJ, Walker DI (1995) The distribution, biomass and primary production of the seagrass Halophila ovalis in the Swan/Canning Estuary, Western Australia. Aquat Bot 51:1-54
Rodriguez LF (2006) Can invasive species facilitate native species? Evidence of how, when, and why these impacts occur. Biol Invasions 8:927-939

Stachowicz JJ (2001) Mutualism, facilitation, and the structure of ecological communities. Bioscience 51:235-246

Staehr PA, Pedersen MF, Thomsen MS, Wernberg T, Krause-Jensen D (2000) Invasion of Sargassum muticum in Limfjorden (Denmark) and its possible impact on the indigenous macroalgal community. Mar Ecol Prog Ser 207:79-88

Thomsen MS, Wernberg T, Altieri AH, Tuya F, Gulbransen D, McGlathery KJ, Holmer M, Silliman BR (2010a) Habitat cascades: the conceptual context and global relevance of facilitation cascades via habitat formation and modification. Integr Comp Biol 50:158-175

Thomsen MS, Wernberg T, Tuya F, Silliman BR (2010b) Ecological performance and possible origin of a ubiquitous but understudied gastropod. Estuar Coast Shelf Sci 87:501-509

Thomsen MS, de Bettignies T, Wernberg T, Holmer M, Debeuf B (2012) Harmful algae are not harmful to everyone. Harmful Alga 16:74-80

Wahl M (2009) Epibiosis ecology, effects and defences ecological studies. Mar Hard Bottom Communities 1(206):61-72

Wernberg T, Tuya F, Thomsen MS, Kendrick GA (2010) Turban snails as habitat for foliose algae: contrasting geographical patterns in species richness explained by top-down control from limpets? Mar Freshw Res 61:1-6

Wonham MJ, O'Connor M, Harley CDG (2005) Positive effects of a dominant invader on introduced and native mudflat species. Mar Ecol Prog Ser 289:109-116 